\section{Patient with Psychosis Undergoing Cheek Reconstruction}

Sang Soo Yu, Hyun-Woo Shin, Pil-Dong Cho, Soo-Hyang Lee

Department of Plastic and Reconstructive Surgery, Ilsan Paik Hospital, Inje University, Goyang, Korea

\begin{abstract}
Correspondence: Hyun-Woo Shin
Department of Plastic and Reconstructive Surgery, Inje University Ilsan Baek Hospital, Inje University College of Medicine, 170 Juhwa-ro, Ilsanseo-gu, Goyang 411-706, Korea

Tel: +82-31-910-7322, Fax:+82-31-910-7814, E-mail: mdshin7@naver.com
\end{abstract}

No potential conflict of interest relevant to this article was reported.

Received: 16 Jul 2013 • Revised: 25 Sep 2013 • Accepted: 2 Oct 2013 pISSN: 2234-6163・ elSSN: 2234-6171

http://dx.doi.org/10.5999/aps.2014.41.2.188 • Arch Plast Surg 2014;41:188-190

Copyright (C) 2014 The Korean Society of Plastic and Reconstructive Surgeons

This is an Open Access article distributed under the terms of the Creative Commons

Attribution Non-Commercial License (http://creativecommons.org/licenses/by-nc/3.0/) which permits unrestricted non-commercial use, distribution, and reproduction in any medium, provided the original work is properly cited.

Psychologically impaired patients may be brought to the emergency room out of control. Although it is too difficult for surgeons to decide on whether to perform a restorative operation under these conditions, uncooperative psychotic patients should not be deprived of early microsurgical restoration. This report presents the approach of a surgeon/psychiatrist team that managed a patient with amphetamine-induced psychosis.

A 30-year-old male with a defect on his left cheek was admitted to the emergency room. He had mutilated himself with a pair of scissors, and was suspected of abusing the substance methamphetamine (Philopon). He was in a drowsy mental state without any aggressive behavior, so there was no need to administer antipsychotics. Based on a physical examination, a $4 \mathrm{~cm} \times 5$ $\mathrm{cm}$ buccal defect involving the oral commissure and the intraoral lining was observed at the left hemiface (Fig. 1). The facial and neck computed tomography showed no evidence of a fracture or a vascular injury, but it did show signs of a diffuse subcutaneous emphysema around the left buccal area. The patient was referred to the neuropsychiatry department so that his depression and psychosis could be properly evaluated. Psychiatrists and nurses observed his behavior in an isolated psychiatric ward. The psychiatrists performed an accurate assessment of his psychiatric problem. After five days of psychiatric management, his suicidal and psychotic tendencies had decreased. The next day, a microsurgical operation was carried out for cheek reconstruction.

Doppler ultrasound was used to check the radial artery, followed by an Allen test before the operation. The bilobed flap is designed to be placed on the volar side of the left forearm, based on the radial artery. One lobe of the flap is used for the reconstruction of the intraoral lining, while the second lobe is used to restore the outer surface of the buccal defect. The size of the flap was $8.5 \mathrm{~cm} \times 5 \mathrm{~cm}$, including the subcutaneous fat (Fig. 2). One radial artery and one radial vein were preserved. The length of the pedicle was 6 $\mathrm{cm}$. When the flap was positioned at the recipient site, the flap was folded to correspond to the dissection margins of the recipient site. One facial artery and

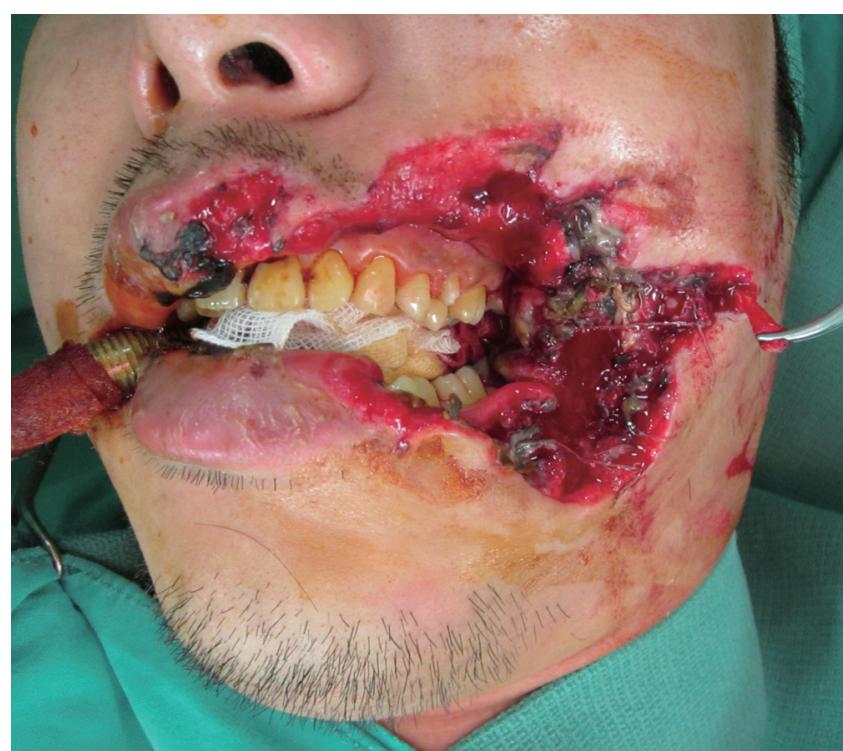

Fig. 1.

Preoperative appearance. A 30-year-male presented with a $4 \mathrm{~cm} \times 5 \mathrm{~cm}$ buccal defect involving the oral commissure and intraoral lining.

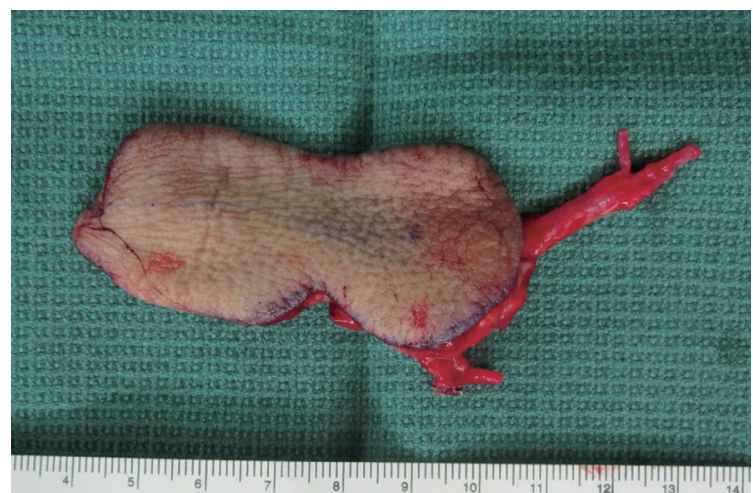

Fig. 2.

The $8.5 \mathrm{~cm} \times 5.0 \mathrm{~cm}$ bilobed folding radial forearm flap. 


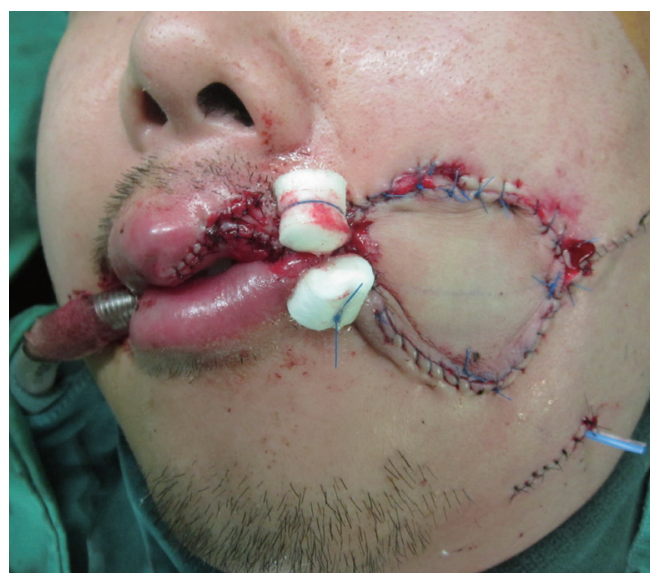

Fig. 3. Postoperative appearance after reconstruction. The radial forearm free flap was inset.
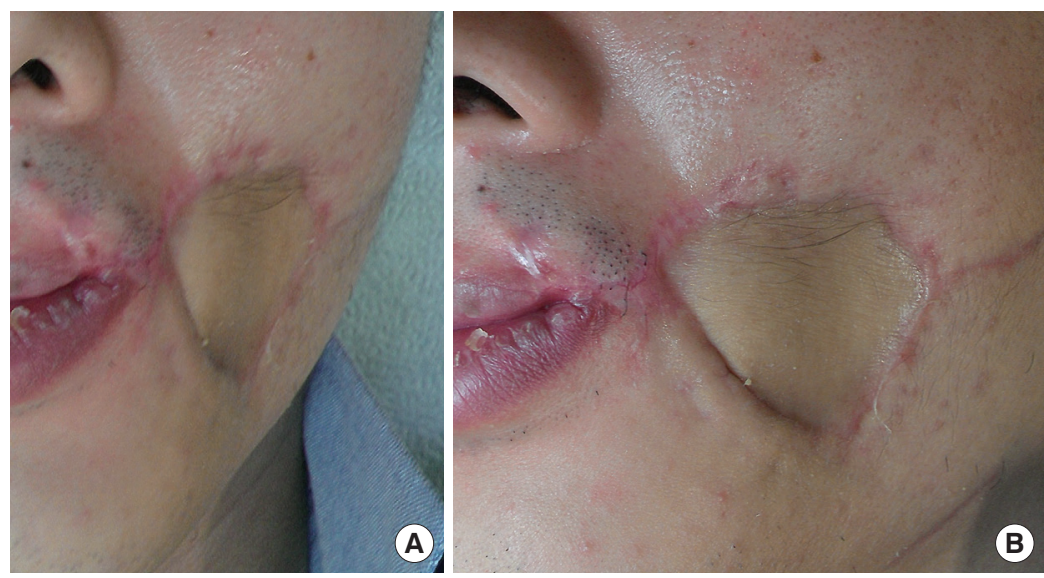

Fig. 4 .

Postoperative results 3 months after surgery. (A) Anterior view. (B) lateral view. The patient showed good wound healing with normal speech and swallowing functions. one facial vein were recipient vessels. Microvascular anastomosis was performed in an end-to-end manner with 10-0 nylon (Fig. 3). The donor site of the left forearm was closed with a split-thickness skin graft from the left thigh.

After the operation, he was moved into a general psychiatric ward with close observation. The postoperative flap control, including color, temperature, and capillary return, was in normal range. The Doppler signal was performed every 2 hours for 5 days. Upper extremity restraint was used to prevent the patient from hurting himself for 3 additional days. However, no bite block was used to protect the flap. Because his psychotic symptoms subsided, the psychiatrists were able to manage his depression using psychological therapy without any anti-psychotics. However, intravenous lorazepam (Ativan, Ildong Phamaceutical Co., Ltd., Seoul, Korea) was used to relieve symptoms such as insomnia and anxiety. After the operation, prostaglandin E (Eglandin, Mitsubishi Tanabe Pharma Korea Co., Ltd., Seoul, Korea) was administered intravenously for 4 days. Intravenous antibiotics were sustained for a period of 3 days, and a heat lamp was used on the flap site for 7 days. The skin-grafted site on the forearm was covered with a vacuum-assisted closure dressing. A short arm splint was applied to ensure immobilization for 2 weeks. Postoperative speech and swallowing functions were deemed acceptable. Moreover, the patient was able to eat a solid diet without any complaints. However, facial expression was not fully recovered, so the patient was somewhat concerned about cosmetic problems during the follow-up period (Fig. 4).
The cheek is the largest aesthetic and functional unit of the face. If the defect is small, local flaps that provide the closest color and contour match are sufficient. However, full-thickness defects on the cheek, including the buccal mucosa and commissure, require specific flaps. The radial forearm flap has been found to be a suitable and useful method. Its thinness, pliability, and ability to maintain a consistent volume and surface area are suitable for intraoral reconstruction, and the flap conforms well to the contours of the oral cavity [1]. Free radial forearm flaps could be easily folded to repair the skin and mucosa. In addition, although the radial forearm flap has a higher donorsite morbidity than other flaps, its anatomic structure is regular, and changing the patient's position is not required during an operation, shortening the operative procedure [2].

Methamphetamine (Philopon) is a psychostimulant and a highly addictive drug. In higher doses, it can induce euphoria, and it can be used to treat narcolepsy and attention deficit/hyperactivity disorder [3]. Upon activating the psychological reward system by triggering a cascading release of dopamine in the brain, it can lead to amphetamine psychosis [4]. Patients with amphetamine psychosis may be uncooperative, and can even be hostile to physicians. Patients with psychological problems also tend to be lost during the follow-up period and refuse postoperative care. Thus, some surgeons may hesitate to perform the appropriate microsurgical operation and prefer to perform a simpler procedure. However, Lin et al. [5] reported that the success rate of free-tissue transfer in psychoneurologically impaired patients is similar to 
that of the population at large, so these patients should not be deprived of the benefits of restorative surgery [5].

In conclusion, this case shows that a microvascular operation with a radial forearm free flap was performed to reconstruct the cheek of a patient suffering from psychosis. If postoperative flap-related complications were to have appeared in the present case, it could have been difficult to manage the problems, considering that the patient's mental state was unstable. Therefore, the authors chose a radial forearm free flap over any type of perforator flap. Despite the psychiatric problems of the patient, the aesthetic and functional outcome was relatively successful. The authors recommend that active microsurgical restoration could be successfully performed using a multidisciplinary approach with psychiatrists to reconstruct posttraumatic facial defects in severely psychotic patients. It should be noted that surgical and psychiatric followup arrangements must be carefully planned before discharge.

\section{References}

1. Kang HG, Park MC, Lim H, et al. Modified folding radial forearm flap in soft palate and tonsillar fossa reconstruction. J Craniofac Surg 2013;24:458-60.

2. Tuncel U, Aytac S. Reconstruction of full-thickness cheek defects with using free osseocutaneous radial forearm flap. J Craniofac Surg 2012;23:e357-9.

3. Bramness JG, Gundersen OH, Guterstam J, et al. Amphetamine-induced psychosis: a separate diagnostic entity or primary psychosis triggered in the vulnerable? BMC Psychiatry 2012;12:221.

4. Cruickshank CC, Dyer KR. A review of the clinical pharmacology of methamphetamine. Addiction 2009; 104:1085-99.

5. Lin $\mathrm{CH}$, Wei FC, Chen CT, et al. Microsurgical tissue transplantation or replantation in patients with psychoneurological impairment. Plast Reconstr Surg 2001;108:1211-7.

\section{Thumb Carpometacarpal Dislocation and Open Dorsal Metacarpophalangeal Instability: A Variation of the Floating Thumb}

Jose Couceiro, Alberto Sanchez, Carlos Pernal, Marcos Sanmartin

Hand Surgery Unit, Orthopaedics Department, POVISA Hospital, Vigo, Spain

Correspondence: Jose Couceiro

Hand Surgery Unit, Orthopaedics Department, POVISA Hospital, Calle Salamanca 5, Vigo 36211, Spain

Tel: +34676230437, Fax: +34986413144,E-mail: couceirox@gmail.com

No potential conflict of interest relevant to this article was reported.

Received: 17 Sep 2013 •Revised: 17 Oct $2013 \bullet$ Accepted: 26 Oct 2013 pISSN: 2234-6163 • elSSN: 2234-6171

http://dx.doi.org/10.5999/aps.2014.41.2.190 • Arch Plast Surg 2014;41:190-192

Copyright (C) 2014 The Korean Society of Plastic and Reconstructive Surgeons

This is an Open Access article distributed under the terms of the Creative Commons Attribution Non-Commercial License (http://creativecommons.org/licenses/by-nc/3.0/) which permits unrestricted non-commercial use, distribution, and reproduction in any medium, provided the original work is properly cited.

With only five individual cases previously reported in the literature $[1,2]$, the simultaneous dislocation of the carpometacarpal (CMC) and metacarpophalangeal (MCP) joints of the thumb without a fracture, also known as the floating thumb metacarpal, is an extremely rare injury.

We present a variation of this uncommon condition that was characterized by the presence of an open dorsal MCP instability and a concomitant CMC dislocation with no associated fractures. To the best

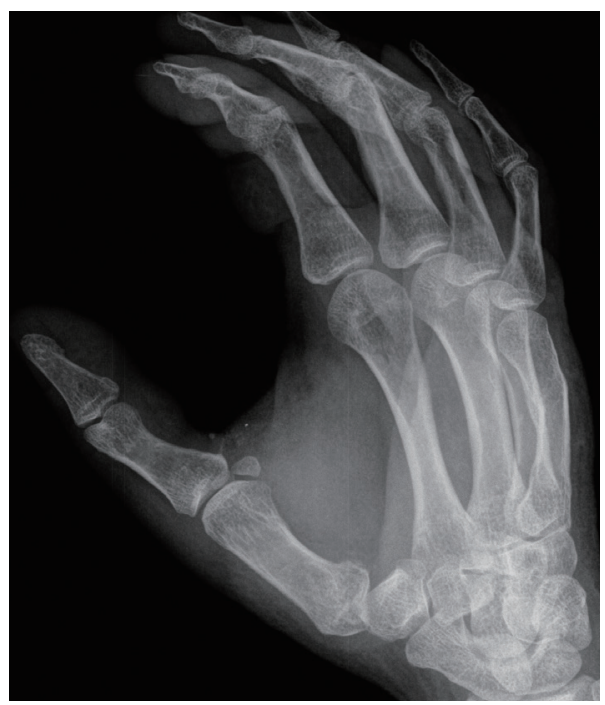

